International Journal of Distributed and Parallel Systems (IJDPS) Vol.3, No.1, January 2012

\title{
THE MULTIPLEXING OF OFDM SIGNALS ON THE DOWNLINK IN UTRAN-FDD
}

\author{
OUESSE Mohamed El - Amine ${ }^{1}$, NGOM Agnès ${ }^{1}$, BOUALLEGUE Ridha ${ }^{2}$, \\ FARSSI Sidi Mohamed ${ }^{3}$ and OUYA Samuel ${ }^{1}$ \\ ${ }^{1}$ Laboratory of Computer, Network and Telecommunications, Cheikh Anta Diop \\ University of Dakar, Dakar, Senegal \\ omea82@yahoo.fr, mameagnes@yahoo.fr, samuel.ouyadgmail.com \\ ${ }^{2}$ Innov'Com Lab in Sup'Com, University of Carthage, Tunis, Tunisia \\ ridha.bouallegue@gmail.com
}

${ }^{3}$ Laboratory of Medical, Imaging and Bioinformatics, Cheikh Anta Diop University of Dakar, Dakar, Senegal

farsism@yahoo.com

\begin{abstract}
The UMTS network is complementary to GSM and GPRS. The GSM network covers the features required for voice-type services in a circuit mode, the network brings GFPRS the first features to the introduction of services such as packet data, and UMTS networks complement these by offering voice and data services on an additional packet. UMTS is thus an extension of GPRS and also works in packet mode. The transmission speed offered by UMTS networks to 2Mbit/s. UMTS infrastructure enables expansion of frequencies as well as changes in data coding. In this paper, the use of OFDM signals in the UMTS access network UTRANFDD and 64QAM modulation allowed us to improve the rate 2Mbit/s to $22.5 \mathrm{Mbit} / \mathrm{s}$. The results, including improved throughput to $22.5 \mathrm{Mbit} / \mathrm{s}$, show us that the power frequency spectrum of a single OFDM signal is centered around the fundamental frequency, but the spectral width of the power spectrum of the OFDM signals is higher than that of the power spectrum is a function that is typically used in UMTS. We also noted that the greater the number of carriers increases, the more important the spectral width is. The multicarrier modulation was based, in our case, on the choice of the multiplexing of signals without noise and with noise.
\end{abstract}

KEYWORDS

OFDM, UMTS, UTRAN-FDD, Multiplexing

\section{1- INTRODUCTION}

The problem that arises in the cellular network is the low flow for packet communications. The cellular network of third-generation UMTS (Universal Mobile Telecommunications System) could satisfy mobile users, by adding services such as access to wireless internet, video telephony, and video messages as well as the reception of television on the phone. But the access network, the UTRAN (UMTS Terrestrial Radio Access Network), the latter, achieves a maximum flow of $2 \mathrm{Mbit} / \mathrm{s}$ per user, which is insufficient for advanced applications, bandwidthintensive. 
Moreover, wireless networks like WiFi[1] are normalized by offering much higher data rates than UMTS, up to 500Mbit/s and therefore allow high-bandwidth applications, like multimedia, for example.

To overcome these difficulties, we suggest a reform of the UTRAN in view of using orthogonal carriers in OFDM, instead of a gate function.

We use the multicarrier techniques, which include transmitting digital data, by modulating a number of carriers simultaneously. We applied these techniques to signals without noise and with noise.

\section{2- MULTIPLEXING OF SIGNALS WITHOUT NOISE}

We consider at the level of a transmitter given, the following hypothesis: $\mathrm{k}$ users want to send information (signals) via a common carrier broadband. Each information is modeled by a sequence of \pm 1 . Let $g_{k}(t)$ the pseudo-random signal with $T$ the length of information bit and $\mathrm{T}_{\mathrm{c}}$ the chip duration of pseudo-random code with $T=L \cdot T_{c}(1)$

In which $\mathrm{L}$ is the number of chip used at the spreading sequence.

$$
\left\{\begin{array}{c}
\mathrm{g}_{\mathrm{k}}(\mathrm{t})=\sum_{\mathrm{n}=0}^{\mathrm{L}-1} \mathrm{a}_{\mathrm{k}}(\mathrm{n}) \cdot \mathrm{ofdm}_{\mathrm{n}}\left(\mathrm{t}-\mathrm{nT}_{\mathrm{c}}\right) \\
\text { for } 0 \leq \mathrm{t} \leq \mathrm{T}
\end{array}\right.
$$

With:

- $\left\{a_{k}\right\}$ a pseudo-random $a_{k}$ is \pm 1 .

- of $d m(t)=\sum_{i=0}^{\mathrm{N}-1} \mathrm{C}_{\mathrm{i}} \mathrm{e}^{\mathrm{j} 2 \pi \mathrm{f}_{\mathrm{i}} \mathrm{t}}$ is the total signal of all data from one OFDM symbol.

- $\mathrm{C}_{\mathrm{i}}$ complex numbers that carry information, defined from bits by a constellation quadrature amplitude modulation (QAM) in multiple states $\left(4,16,64, \ldots, 2^{q}\right)$. Assuming $C_{i}=\alpha_{\mathrm{i}}+\mathrm{j} \beta_{\mathrm{i}}$ then $\operatorname{ofdm}(\mathrm{t})=\sum_{\mathrm{i}=0}^{\mathrm{N}-1}\left(\alpha_{\mathrm{i}}+\mathrm{j} \beta_{\mathrm{i}}\right) \mathrm{e}^{\mathrm{j} 2 \pi \mathrm{f}_{\mathrm{i}} \mathrm{t}}$

We multiplexe the information by combining each with a vector $g_{k}$. Thus we get the packet of bits of length $\mathrm{N}: b_{k}=\left[b_{k}(1), \ldots, b_{k}(N)\right]^{t}$. The signal becomes:

$s_{k}(t)=\sqrt{\xi_{k}} \sum_{m=1}^{M} b_{k}(m) g_{k}(t-m T)$

In which $\xi$ represents the signal energy per byte and $b_{k}(m)$ is the spreading code that handles the multiplexing of multiple channels from a single source. Each source can use all codes.

$$
\begin{array}{r}
\mathrm{g}_{\mathrm{k}}(\mathrm{t}-\mathrm{mT})=\sum_{\mathrm{n}=0}^{\mathrm{N}-1} \mathrm{a}_{\mathrm{k}}(\mathrm{n}) \cdot \operatorname{ofdm}_{\mathrm{n}}\left(\mathrm{t}-\left(\mathrm{m}+\frac{\mathrm{n}}{\mathrm{L}}\right) \mathrm{T}\right) \\
\mathrm{g}_{\mathrm{k}}(\mathrm{t}-\mathrm{mT})=\sum_{\mathrm{n}=0}^{\mathrm{N}-1} \mathrm{a}_{\mathrm{k}}(\mathrm{n}) \sum_{\mathrm{i}=0}^{\mathrm{I}-1} \mathrm{C}_{\mathrm{i}} \mathrm{e}^{\mathrm{j} 2 \pi \mathrm{f}_{\mathrm{i}}\left(\mathrm{t}-\left(\mathrm{m}+\frac{\mathrm{n}}{\mathrm{L}}\right) \mathrm{T}\right)} \\
s_{k}(\mathrm{t})=\sqrt{\xi_{k}} \sum_{m=1}^{M} b_{k}(m) \sum_{\mathrm{n}=0}^{\mathrm{N}-1} \mathrm{a}_{\mathrm{k}}(\mathrm{n}) \sum_{\mathrm{i}=0}^{\mathrm{I}-1} \mathrm{C}_{\mathrm{i}} \mathrm{e}^{\mathrm{j} 2 \pi \mathrm{f}_{\mathrm{i}}\left(\mathrm{t}-\left(\mathrm{m}+\frac{\mathrm{n}}{\mathrm{L}}\right) \mathrm{T}\right)}
\end{array}
$$

Then we couple all users and the signal becomes :

$S(t)=\sum_{k=1}^{K} s_{k}\left(t-\tau_{k}\right)$ with $0 \leq \tau_{k}<T$ for $1 \leq k \leq K$ 
International Journal of Distributed and Parallel Systems (IJDPS) Vol.3, No.1, January 2012

And $\tau_{k}$ represents the transmission delay for user $\mathrm{k}$. If we consider that the signals are synchronous then $\tau_{k}=0$ and the transmitted signal becomes:

$$
\begin{array}{r}
S(t)=\sum_{k=1}^{K} s_{k}(t)=\sum_{k=1}^{K} \sqrt{\xi_{k}} \sum_{m=1}^{M} b_{k}(m) g_{k}(t-m T) \\
S(t)=\sum_{k=1}^{K} \sqrt{\xi_{k}} \sum_{m=1}^{M} b_{k}(m) \sum_{\mathrm{n}=0}^{\mathrm{N}-1} \mathrm{a}_{\mathrm{k}}(\mathrm{n}) \sum_{\mathrm{i}=0}^{\mathrm{I}-1} \mathrm{C}_{\mathrm{i}} \mathrm{e}^{\mathrm{j} 2 \pi \mathrm{f}_{\mathrm{i}}\left(\mathrm{t}-\left(\mathrm{m}+\frac{\mathrm{n}}{\mathrm{L}}\right) \mathrm{T}\right)}
\end{array}
$$

We consider that the signal multiplexing OFDM is orthogonal. And if the space between the frequencies is $1 / T_{s}$ then $f_{i}=f_{0}+\frac{i}{T_{s}}$ and replacing $\mathrm{C}$ by its values, then:

$S(t)=\sum_{k=1}^{K} \sqrt{\xi_{k}} \sum_{m=1}^{M} b_{k}(m) \sum_{\mathrm{n}=0}^{\mathrm{N}-1} \mathrm{a}_{\mathrm{k}}(\mathrm{n}) \sum_{\mathrm{i}=0}^{\mathrm{I}-1}\left(\alpha_{\mathrm{i}}+\mathrm{j} \beta_{\mathrm{i}}\right) \mathrm{e}^{\mathrm{j} 2 \pi\left(f_{0}+\frac{i}{T_{S}}\right)\left(\mathrm{t}-\left(\mathrm{m}+\frac{\mathrm{n}}{\mathrm{L}}\right) \mathrm{T}\right)}$

And also $s_{k}(t)=\sqrt{\xi_{k}} \sum_{m=1}^{M} b_{k}(m) \sum_{\mathrm{n}=0}^{\mathrm{N}-1} \mathrm{a}_{\mathrm{k}}(\mathrm{n}) \sum_{\mathrm{i}=0}^{\mathrm{I}-1}\left(\alpha_{\mathrm{i}}+\mathrm{j} \beta_{\mathrm{i}}\right) \mathrm{e}^{\mathrm{j} 2 \pi\left(f_{0}+\frac{i}{T_{s}}\right)\left(\mathrm{t}-\left(\mathrm{m}+\frac{\mathrm{n}}{\mathrm{L}}\right) \mathrm{T}\right)}$

\section{3- MULTIPLEXING OF SIGNALS WITH NOISE}

Let a signal $\mathrm{S}(\mathrm{t})$ consisting of sequences $\mathrm{S}_{\mathrm{k}}(\mathrm{t})$ and a noise $\mathrm{B}(\mathrm{t})$ be.

$\mathrm{S}(\mathrm{t})=\sum_{\mathrm{k}=1}^{\mathrm{K}} \mathrm{S}_{\mathrm{k}}(\mathrm{t})+\mathrm{B}(\mathrm{t})(11)$

The signals $S(t)$ form a discrete set of signals of finite energy $E(S)$ of duration $T_{s}$.

$\mathrm{E}(\mathrm{S})=\int_{0}^{\mathrm{T}_{\mathrm{s}}} \mathrm{S}^{2}(\mathrm{t}) \mathrm{dt}=\mathrm{cte}$

As any function or some random finite energy on $(0, \mathrm{Ts})$ can be regarded as a vector of Hilbert, in case the noise introduced by the transmission; $B_{k}$ projections are then random variables defined by equation (13):

$\mathrm{B}(\mathrm{t})=\sum_{\mathrm{k}=1}^{\infty} \mathrm{B}_{\mathrm{k}} \cdot \varphi_{\mathrm{k}}(\mathrm{t}) \quad$ avec $\mathrm{B}_{\mathrm{k}}=<\varphi_{\mathrm{k}}, \mathrm{B}>(13)$

So we can rough estimate that $: S(t)=\sum_{k=1}^{K} S_{k}(t)+\sum_{k=1}^{K} B_{k} \varphi_{k}(t)$

$$
S(t)=\sum_{k=1}^{K}\left(S_{k}(t)+B_{k} \varphi_{k}(t)\right)
$$

With $s_{k}(t)=\sqrt{\xi_{k}} \sum_{m=1}^{M} b_{k}(m) \sum_{\mathrm{n}=0}^{\mathrm{N}-1} \mathrm{a}_{\mathrm{k}}(\mathrm{n}) \sum_{\mathrm{i}=0}^{\mathrm{N}-1}\left(\alpha_{\mathrm{i}}+\mathrm{j} \beta_{\mathrm{i}}\right) \mathrm{e}^{\mathrm{j} 2 \pi\left(f_{0}+\frac{i}{T_{S}}\right)\left(\mathrm{t}-\left(\mathrm{m}+\frac{\mathrm{n}}{\mathrm{L}}\right) \mathrm{T}\right)}$

Thus we have

$$
\begin{array}{r}
S(t)=\sum_{k=1}^{K}\left(\sqrt{\xi_{k}} \sum_{m=1}^{M} b_{k}(m) \sum_{\mathrm{n}=0}^{\mathrm{N}-1} \mathrm{a}_{\mathrm{k}}(\mathrm{n}) \sum_{\mathrm{i}=0}^{\mathrm{N}-1}\left(\alpha_{\mathrm{i}}+\mathrm{j} \beta_{\mathrm{i}}\right) \mathrm{e}^{\mathrm{j} 2 \pi\left(f_{0}+\frac{i}{T_{S}}\right)\left(\mathrm{t}-\left(\mathrm{m}+\frac{\mathrm{n}}{\mathrm{L}}\right) \mathrm{T}\right)}+B_{k} \varphi_{k}(t)\right) \\
S(t)=\sum_{k=1}^{K}\left(\sqrt{\xi_{k}} \sum_{m=1}^{M} b_{k}(m) \sum_{\mathrm{n}=0}^{\mathrm{N}-1} \mathrm{a}_{\mathrm{k}}(\mathrm{n}) \sum_{\mathrm{i}=0}^{\mathrm{N}-1}\left(\alpha_{\mathrm{i}}+\mathrm{j} \beta_{\mathrm{i}}\right) \mathrm{e}^{\mathrm{j} 2 \pi\left(f_{0}+\frac{i}{T_{S}}\right)\left(\mathrm{t}-\left(\mathrm{m}+\frac{\mathrm{n}}{\mathrm{L}}\right) \mathrm{T}\right)}+B_{k} \varphi_{k}(t)\right)
\end{array}
$$


If we consider, that the noise introduced is Gaussian, then its spectral density is $\gamma(v)=\frac{N_{0}}{2}$ and the correlation function is thereby $C_{B}(\tau)=\frac{N_{0}}{2} \delta(\tau)$. Therefore, the noise $B(t)$ is represented by a random vector whose components are $B_{k}$. B is Gaussian random variables independent of the variance $\frac{N_{0}}{2}$.

\section{4- OFDM SYSTEM}

\subsection{Principle}

The principle of OFDM qconsists in dividing a stream of symbols at a rate $\frac{1}{T}$ symbol streams at the rate $\frac{1}{N T}$ each. And N symbols are transmitted in parallel over a period NT. The bandwidth is divided into $\mathrm{N}$ sub-bands below each to the coherence bandwidth of the channel (provided that $\mathrm{N}$ is sufficiently large), which explains the robustness of this modulation in the presence of frequency selective channels.

\subsection{Advantages}

OFDM has the following advantages:

- The main advantage of OFDM lies in the simplicity of the equalization of channel distortions. Contrary to single carrier systems in which attenuation correction of the channel requires a matrix inversion often complex to implement, OFDM has the ability to equalize this effect by simple multiplication by a coefficient of equalizer on each sub-carrier;

- In addition, in a single carrier system, when the sampling frequency increases, the number of coefficients to estimate the channel increases, and thus increases the complexity of the receiver itself, which is not the case for OFDM which requires just a single estimate whatever the sampling frequency may be;

- On the other hand, OFDM has an effective use of allocated frequency band using orthogonal carriers.

\subsection{Disavandtages}

OFDM has some disadvantages. We distinguish:

- OFDM has some weaknesses compared to single-carrier system. Indeed, a simple channel equalization in OFDM loses the diversity gain. In addition, a severe selective fading channel to a given carrier could lose the whole information posted on it [11] which explains the dramatic effect of performances of uncoded OFDM. Generally, methods based on coding (convolutional coding, diversity constellation, turbo code ...) are used with interleaving to combat such fading.

- So, OFDM is very sensitive to synchronization errors [12] [13]. They create interferences between subcarriers and destroy the orthogonality of subcarriers.

- Finally, OFDM is sensitive to nonlinear distortions introduced by the power amplifier of the transmitter, which destroys the orthogonality of subcarriers.

\section{5- WB-CDMA TECHNOLOGY}

WB-CDMA technology is the access code division multiple systems using direct sequence modulation (DS-WB-CDMA). This shows that the bits corresponding to user data are multiplied by a sequence of bits having particular characteristics over a wide bandwidth. Then, 
there is a spread spectrum. This latter broadens the spectrum of a transmission to make it gain strength. It exists two families of codes:

$>$ The channelization codes commonly called orthogonal codes to variable spreading factor (OVSF: Orthogonal Variable Spreading Factor) are characterized by their orthogonality, what is allowing the receiver to separate the signals transmitted on the same frequency band simultaneously;

$>$ scrambling codes commonly called Scrambling codes are pseudo-random (PN: Username Noise) characterized by a perfect autocorrelation property.

The functions of each type of code are summarized in Table 2.1.

Table 2.1. Features channelization codes and scrambling [2] and [14]

\begin{tabular}{|c|c|c|}
\hline Functionalities & Code of channeling & Code of scrambling \\
\hline Usage & $\begin{array}{c}\text { Uplink: Channel separation } \\
\text { DPDCH and DPCCH from the } \\
\text { same terminal. } \\
\text { Downlink : Separation of } \\
\text { connections of different users of the } \\
\text { same cell }\end{array}$ & $\begin{array}{l}\text { Uplink : Separation of the long } \\
\text { terminal code sequence: } 2^{24}-1 \\
\text { Downlink : Cell separation code } \\
\text { short sequence : } 2^{18}-1\end{array}$ \\
\hline Length & $\begin{array}{c}\text { Uplink : } 4 \text { à } 252 \text { chips ( } 1 \text { à } 66,7 \mu \mathrm{s} \text { ) } \\
\text { Downlink : } 512 \text { chips }\end{array}$ & $\begin{array}{l}\text { Uplink : } 10 \mathrm{~ms}=38400 \text { chips ou } \\
66,7 \mu \mathrm{s}=256 \text { chips } \\
\text { Downlink }: 10 \mathrm{~ms}=38400 \text { chips }\end{array}$ \\
\hline $\begin{array}{l}\text { Number of } \\
\text { codes }\end{array}$ & $\begin{array}{l}\text { Number of codes equal to } \\
\text { the spreading factor }\end{array}$ & $\begin{array}{l}\text { Uplink : several million } \\
\text { Downlink : } 512\end{array}$ \\
\hline $\begin{array}{l}\text { Family } \\
\text { of codes }\end{array}$ & $\begin{array}{c}\text { Orthogonal Variable Spreading } \\
\text { Factor (OVSF ) }\end{array}$ & $\begin{array}{c}10 \text { ms: Gold code } \\
66,7 \mu \mathrm{s}: \text { Extended } S(2) \text { code }\end{array}$ \\
\hline Spreading & $\begin{array}{c}\text { yes } \\
\text { Increase the bandwidth }\end{array}$ & $\begin{array}{c}\text { No } \\
\text { No change in the bandwidth }\end{array}$ \\
\hline
\end{tabular}

The term flow is $D=\frac{N \cdot R}{T_{S}+\Delta} \log _{2}(M)$.

In which $\mathrm{N}$ is the number of carrier, $\mathrm{R}$ is the efficiency of coding, Ts is the symbol duration, $\Delta$ is the guard interval and $\mathrm{M}$ is the number of states.

WB-CDMA technique which is reserved for transmission systems and digital signal processing must be able to support multimedia applications requiring broadband. For 64 QAM modulation in a yield of coding $\mathrm{R}=3 / 4, \mathrm{Ts}=2.5 \mu \mathrm{s}, \Delta=0, \mathrm{~N}=1000$, the theoretical bandwidth available can reach up to $22.5 \mathrm{Mbit} / \mathrm{s}$.

This system is possible through the use of OFDM (Orthogonal Frequency Division Multiplexing). 
We have studied the evolution of the flow depending on the number of carriers and taking into account the bit error rate (BER) (17):

$T E B=4\left(1-\frac{1}{\sqrt{M}}\right) \cdot \frac{1}{2} \operatorname{erf} c(\sqrt{\gamma})$ with $\gamma=\frac{E_{b}}{N_{0}} \gamma$ is the signal to noise ratio.

From equation (17), we derive the number of states M (18)

$M=\left(\frac{1}{1-\frac{T E B}{2 \operatorname{erfc}(\sqrt{\gamma})}}\right)^{2}$

By replacing $M$ by its expression in the relationship (16) giving flow, we have finally the relationship between flow rate and the number of carriers set by the bit error rate BER (19).

$D=\frac{2 . N \cdot R}{T_{S}+\Delta} \log _{2}\left(\frac{1}{1-\frac{T E B}{2 \operatorname{erfc}(\sqrt{\gamma})}}\right)$

Figure 1 shows the evolution of the flow depending on the number of carriers for values of bit error rate fixed.

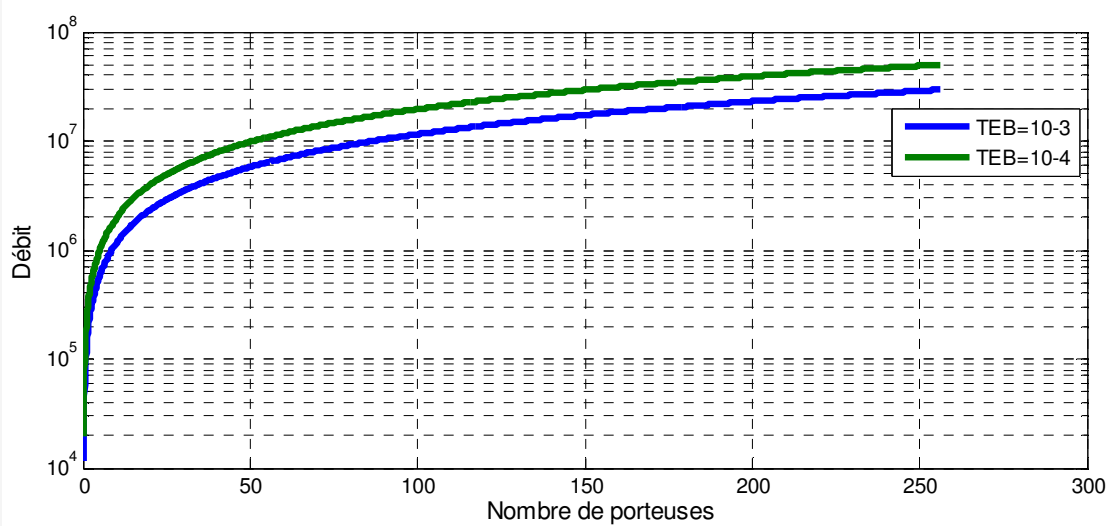

Figure 1: the flow depending on the number of carriers set by the BER.

We note that reducing the bit error rate increases the rate which is based on the number of carriers. UTRAN-FDD mode is based on the multiple access technique WB-CDMA technology which corresponds to the DS-CDMA (Direct Sequence CDMA) with a spread over a $5 \mathrm{MHz}$ bandwidth [2]. The frequency range of UMTS is [1920 - $1980 \mathrm{MHz}$ ] for the uplink bandwith and [2110 - $2170 \mathrm{MHz}$ ] for the downlink bandwith [2][3].

\section{6- RESULTS OF THE USE OF MULTIPLEXING OFDM SIGNALS}

\section{IN A UMTS NETWORK}

As the Fourier transform of a real function is the power spectrum is an even and symmetrical function. But it also includes negative frequencies.

The simulation results of the power spectrum are presented in two (02) categories: first, the power $(\mathrm{dBm})$ is positive. So an "amplification" is in question. Figures 2, 3 and 4 respectively illustrate the frequency spectrum of a carrier and different carriers, the frequency spectrum of a

function and the signal for 10 carriers OFDM and OFDM signal spectrum for 15 and 20 carriers. 
International Journal of Distributed and Parallel Systems (IJDPS) Vol.3, No.1, January 2012
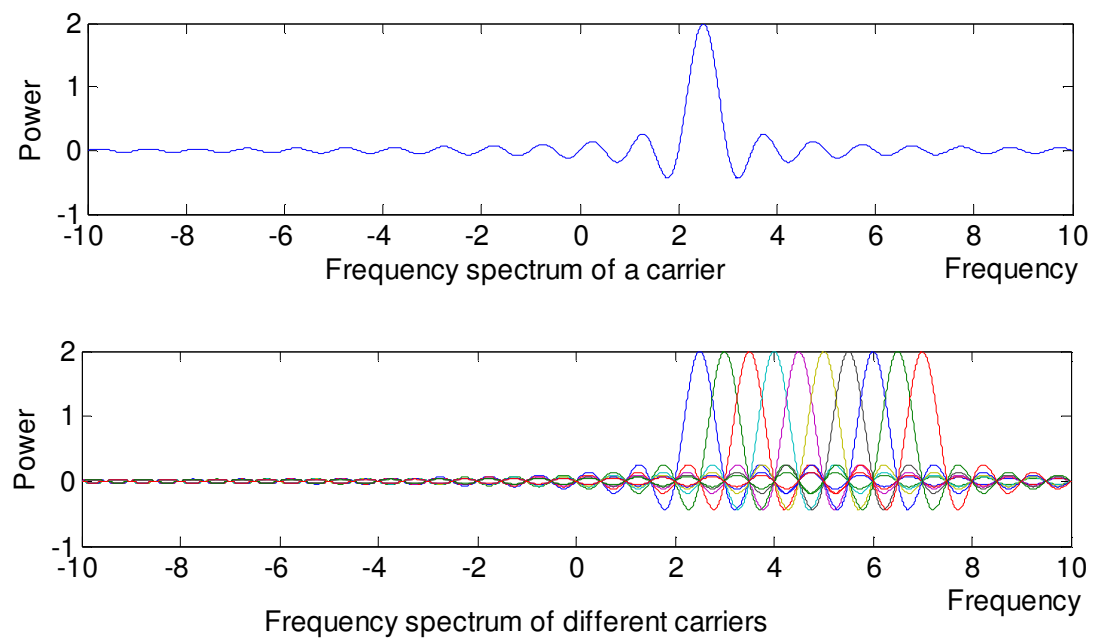

Figure 2: Spectrum of a carrier frequency and different carriers

The overlay spectra $S_{k}(f)$ ( $\mathrm{k}=1$ to 10$)$ shows that one of these spectra is at maximum while others are stabilized at zero ( 0$)$ and also at this level that there is a partial recovery of the next spectrum. As the frequencies are orthogonal, it is assumed that the B band signal is constant while increasing the number of carriers does not increase the flow because $B=1 / T s B=1 / T_{s}$ $=\Delta \mathrm{f}$, but the spacing between carriers $(\Delta \mathrm{f})$ decreases. And if $(\Delta \mathrm{f})$ is constant, then increase the number of carriers increased throughput but also the signal band.
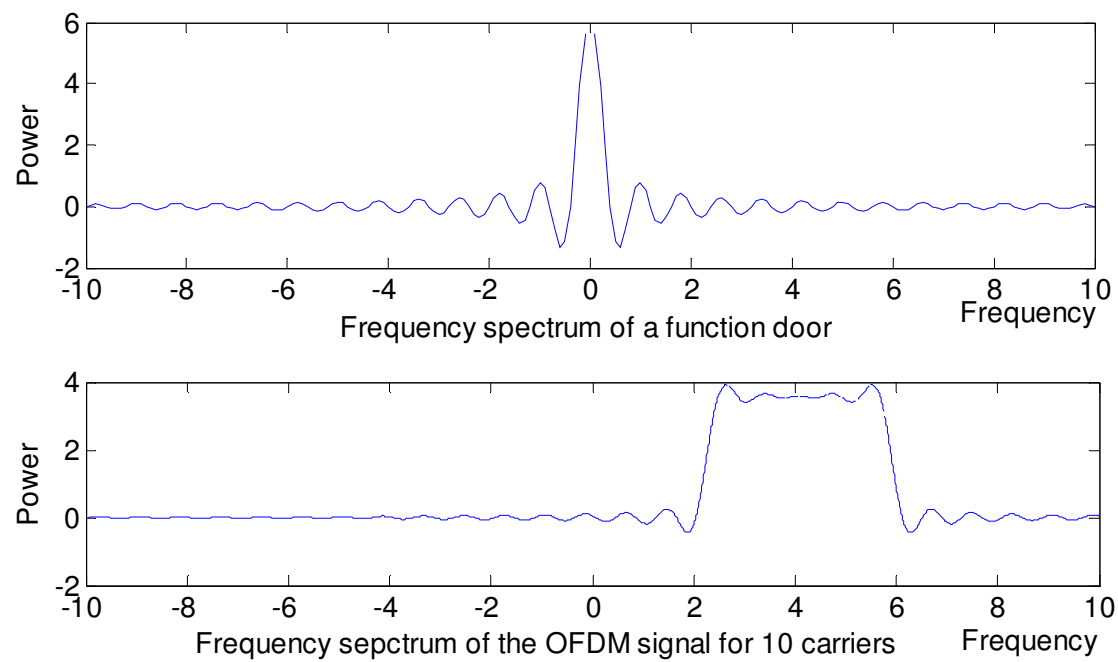

Figure 3: Frequency Spectrum of a function of the OFDM signal door and for 10 carriers

We see that, the spectrum $\mathrm{S}(\mathrm{f})$ of the 10 carrier OFDM signal has a bandwidth (between 2.05 and 6.11) much higher than spectrum function is (between -0.5 and 0.5 ). 
International Journal of Distributed and Parallel Systems (IJDPS) Vol.3, No.1, January 2012
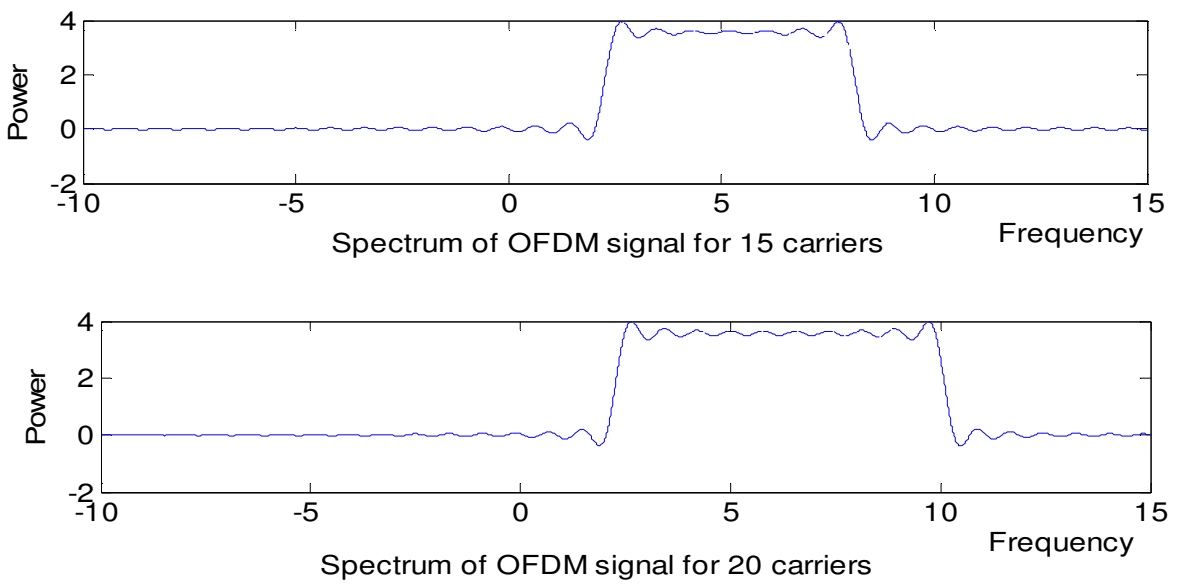

Figure 4: Spectrum of OFDM signal for 15 and 20 carriers.

We note that the bandwidth of 20 carriers (between 2.05 and 10.31) is greater than 15 carriers (between 2.05 and 8.35). Therefore, the greater the number of carriers is, the greater is the size of the spectrum.

And secondly, the power $(\mathrm{dBm})$ is negative, then one speaks of a "mitigation". Figure 5 and Figure 6 show respectively the attenuation spectrum of a carrier and the various carriers and the attenuation of a spectrum is a function of the OFDM signal and for 10 carriers.
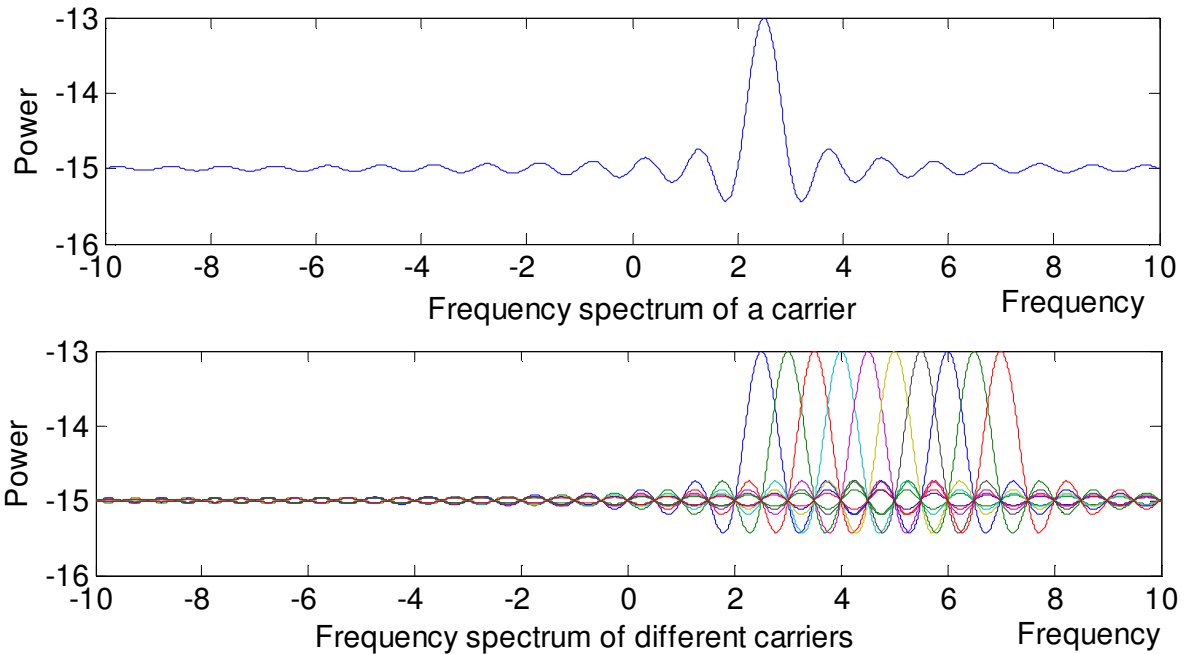

Figure 5: The attenuation spectrum of a carrier and different carriers 
International Journal of Distributed and Parallel Systems (IJDPS) Vol.3, No.1, January 2012
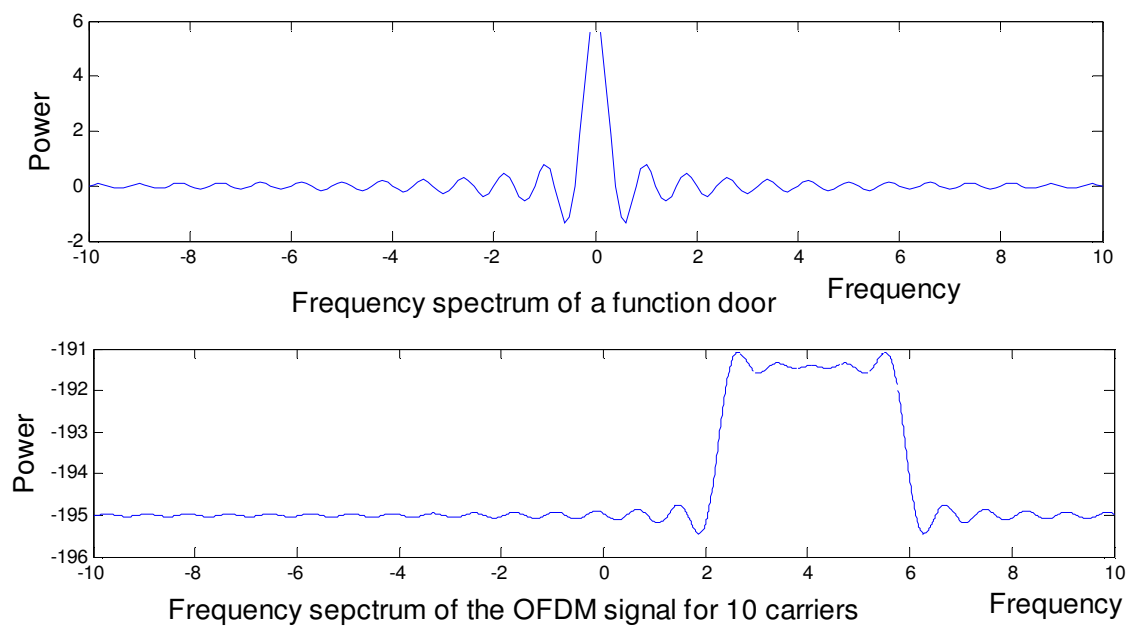

Figure 6: Attenuation of a spectrum of a function of the door and for 10 carrier OFDM signal

We note that, on the last two figures, the power had some negative values whatever the value of the frequency spectrum but the shape remains almost the same as Figure 2, Figure 3 and Figure 4.

We point out to your aattention that the multiplication of the power spectrum by an equal number of +1 or -1 does not change its power.

\section{7- CONCLUSION}

In this paper, we made a study of multiplexing signals on the downlink OFDM in UTRANFDD simulation. The results show that the power spectrum of an OFDM signal is centered around its fundamental frequency. But also the sum of power spectra of OFDM signals has a bandwidth greater than that of a power spectrum function which was used in the past. So the use of OFDM signals by the simulation allowed us to improve the flow, which was estimated at $2 \mathrm{Mbit} / \mathrm{s}$ to $22.5 \mathrm{Mbit} / \mathrm{s}$.

Finally, the more the number of carriers increase, the more the band of spectrum is important and the more status and more QAM increases the data rate.

\section{REFERENCES}

[1] P. MÜHLETHALER «802.11 et les réseaux sans fil », Paris, Eyrolles, 2002.

[2] S. TABBAnE, M. T. MISSAOUI «Pratique de l'ingénierie des réseaux cellulaires », Paris, Hermes, 2006.

[3] L. THIERRY "Principes de radiocommunication de troisième génération », Paris, Vuibert, 2002.

[4] Y. LOUËT « Les modulations multi-porteuses », Colloque GEII, Rennes, 2010.

[5] T. SAÏDI, O. SENTIEYS, S. ROY «Prototype MIMO temps réel pour l'UMTS ». MajecSTIC

Rennes 2005, pp 232-237 
International Journal of Distributed and Parallel Systems (IJDPS) Vol.3, No.1, January 2012

[6] A. CHOKRI, M. MOHAMED «Destination d'un code aux systèmes à multiplexage fréquentiel, orthoganal (OFDM) : Décodage par l'algorithme de VITERBI ». SETIT 2007

[7] A. MASMOUDI, S. TABBANE, D. ZEGHLACHE « Dimensionnement des Réseaux UMTS Basés sur la technique HSDPA » SETIT 2007.

[8] L. FATHI, P LOUBATON «Estimation du SINR pour le lien descendant de l'UMTS-FDD ». XXIIe colloque GRETSI (traitement du signal et des images), Dijon (FRA), 8-11 septembre 2009, http://documents.irevues.inist.fr/bitstream/handle/2042/29133/fathi_524.pdf? sequence $=1$ consulté : 6 Septembre 2011

[9] S. MAZLOUT, S. TABBANE «Etude d'allocation de ressources sur le lien descendant en UTRAN-FDD », MS3G 2001, Lyon (France), Décembre 2001

[10] J. LAINE, P. VIGNERON «Télécommunications numériques : Le CDMA », MODEX 2001

[11] R. VAN NEE, R PRASAD «OFDM for wireless multimedia communication $s » ; 1^{\text {st }}$ edition Artech House Norwood, MA USA , 2000.

[12] T. POLLET, M. VAN BALDEL MOENECLAEY M.; «BER sensitivity of OFDM systems to carrier frequency offset and Wiener phase noise »;IEEE Tansaction on Communications 1995; Vol. 43; pp. 191-193.

[13] T. POLLET, M. MOENECLAEY; I. JEANCLAUDE , H. SARI «Effect of Carrier phase jitter sensitivity for single-carrier and multi-carrier QAM systems»;in proc. IEEE international conference on communications (ICC 95), Seaule, USA, pp.1046-1050, June 1995.

[14] HARRI Holma et ANTTI Toskala, «UMTS :Les réseaux mobiles de troisième génération », Paris, OEM, 2001

[15]R PRASAD, «OFDM for Wireless Communications Systems», London, Artech House, 2004 